RUNNING HEAD: CATEGORIES CONVEY PRESCRIPTIVE INFORMATION ACROSS DOMAINS

Categories convey prescriptive information across domains and development

Emily Foster-Hanson ${ }^{1}$, Steven O. Roberts ${ }^{2}$, Susan A. Gelman ${ }^{3}$, and Marjorie Rhodes ${ }^{4}$

${ }^{1}$ Department of Psychology, Princeton University

${ }^{2}$ Department of Psychology, Stanford University

${ }^{3}$ Department of Psychology, University of Michigan

${ }^{4}$ Department of Psychology, New York University

In press at Journal of Experimental Child Psychology

Send all correspondence to:

Emily Foster-Hanson

Department of Psychology

Princeton University

Peretsman-Scully Hall

Princeton, NJ 08540

Phone: (609) 258-9821

Email: emily.fosterhanson@princeton.edu

Research reported in this publication was supported by National Science Foundation grant BCS 1729540 (to M.R.) and by the Eunice Kennedy Shriver National Institute of Child Health \& Human Development of the National Institutes of Health under Award Number F31HD093431 (to E. F. H.). The content is solely the responsibility of the authors and does not necessarily represent the official views of the National Institutes of Health or the National Science Foundation. We thank Ericka Barroso, Amira Daoud, Emily Green, Arb Kasemsantitham, Mansee Khurana, Garin Kim, Rachel Leshin, Chase Love, Rihab Mahmood, Gabriela Memba, Daryl Ocampo, Louis Peng, Rashel Reizin, and Christine Tai for assistance with data collection. 


\begin{abstract}
Young children display a pervasive bias to assume that what they observe in the world reflects how things are supposed to be. The present studies examined the nature of this bias, by testing whether it reflects a particular form of reasoning about human social behaviors or a more general feature of category representations. Children ages 4-9 and adults $(N=747)$ evaluated instances of nonconformity among members of novel biological and human social kinds. Children held prescriptive expectations for both animal and human categories-in both cases, they said it was wrong for a category member to engage in category-atypical behavior. These prescriptive judgments about categories depended on the extent to which people saw the pictured individual examples as representative of coherent categories. Thus, early prescriptive judgments appear to rely on the interplay between general conceptual biases and domainspecific beliefs about category structure.
\end{abstract}

Keywords: conceptual development; prescriptive judgments; social cognition; biological reasoning

Data and materials: https://osf.io/cbf59/ 


\section{Categories convey prescriptive information across domains and development}

Categories are a powerful means of storing descriptive information about the world. For instance, the concept "children" allows people to infer that any particular child they encounter is not fully grown, has limited decision-making abilities, and probably attends school (Gelman \& Coley, 1990; Gelman \& Markman, 1986; Rips, 1995). Category knowledge also supports prescriptive inferences about what category members should do. For instance, people believe that children should not drive cars, vote, or skip school. Children think about and try to enforce category-related prescriptive expectations from early in development (e.g., saying that boys cannot wear pink, that babies should drink milk, and so on). This kind of prescriptive social reasoning is often described as developing in the context of children's early social interactions (Piaget, 1932; Rakoczy \& Schmidt, 2013; Rakoczy et al., 2008; Rutland, Killen, \& Abrams, 2010; Searle, 1995; Smetana, 1981; Tomasello, 2019a; 2019b). Yet, children (and adults) also reason prescriptively outside of the social domain (e.g., thinking that dogs should bark, and that there is something wrong with a dog that does not; Haward et al., 2018; Prasada \& Dillingham, 2006; 2009). To what extent does prescriptive reasoning about human social behavior as well as behaviors in other domains reflect shared cognitive processes and developmental origins? To address this question, here we directly compare children's prescriptive reasoning about categories of people and of non-human animals (hereafter, "animals") across development.

\section{Prescriptive Judgments About Human Social Behavior}

Prescriptive judgments are an early-emerging and fundamental aspect of social cognition. By age 3, children understand social norms as prescriptive, abstract, and generalizable (Rakoczy, 2008; Rakoczy et al., 2008). For example, adults and preschoolers use the pronoun you in the generic sense (i.e., referring to people in general) in the context of both descriptive regularities (e.g., how one generally uses a hammer) and prescriptive normative conventions (e.g., how one should use a hammer; Orvell et al., 2017; 2018). Young children also actively enforce prescriptive norms; for example, 3-year-olds spontaneously protest against 
norm violations in rule-based games (Schmidt \& Rakoczy, 2017). Although some prescriptive social norms are explicitly communicated to children (Chalik \& Rhodes, 2015; Dahl \& Campos, 2013; Shweder et al., 1987), children also appear "promiscuously normative" (Schmidt et al., 2011)—ready to infer prescriptive social norms quickly and generalize them broadly. For example, young children imitate functionally irrelevant aspects of behavior, suggesting that they interpret others' actions as communicating prescriptive norms (how one is supposed to do an activity) that extend beyond the actor's functional goals (Kenward et al., 2011; Lyons et al., 2007; Nielsen \& Tomaselli, 2010; Schmidt et al., 2016). Preschool-age children even reject the possibility of events that violate social or moral norms, saying that it would be impossible for someone to steal or tell a lie (Chernyak et al., 2013; Kalish, 1998; Phillips \& Cushman, 2017; Shtulman \& Phillips, 2018; Tisak \& Turiel, 1988).

Prescriptive expectations are particularly prominent in children's reasoning about human social categories. For instance, when introduced to made-up categories of people marked only by novel labels (e.g., "This person is a Lissian"), young children expected members of the same category to share the same prescriptive norms (e.g., that two Lissians are both supposed to eat the same kind of food and wear the same kind of clothes) more than other types of properties (e.g., they might not expect that both Lissians will like the same foods or clothing; Kalish, 2012; Kalish \& Lawson, 2008). Young children also track shared prescriptive norms to make categorization decisions (e.g., assuming people with similar obligations are members of the same group; Clement et al., 2011; Foster-Hanson \& Rhodes, 2019b; Kalish \& Cornelius, 2007). Further, 4- to 6-year-old children assume that properties shared across members of a group of people reflect prescriptive norms (an example of descriptive-to-prescriptive reasoning). To illustrate, Roberts, Gelman, and Ho (2017a) introduced children ages 4-13 and adults to novel, made-up groups of people marked by clothing color and novel labels). Children then heard about common features of each group (e.g., members of one group eat one kind of food, and members of another eat a different kind), and then heard about an individual member of one 
group engaging in a behavior that either conformed or did not conform to their group (e.g., a new group member who either ate the same food as their other group members or the food associated with the other group). Children were not given any explicit prescriptive informationthey were told what the group members did, not what they were supposed to do. But nevertheless, younger children ages 4-6 (and older children ages 7-13 to a lesser extent) judged that it was wrong for members of these categories to violate group regularities (e.g., to eat a different kind of food from their group). In contrast, adults generally approved of nonconformity. When the regularity was shown only in a single individual, however, participants of all ages were generally approving (see also Roberts et al., 2017b). These results suggest that children rapidly infer that people who are members of the same social category share the same prescriptive norms. These results are particularly striking given that the social groups in question were completely novel, participants were not members of either group, and the behaviors were neutral in valence (see also Roberts et al., 2019; Rottman \& Kelemen, 2012). Thus, children's evaluations appear to reflect abstract expectations that human social category membership determines how members should behave (see Rhodes, 2013).

In thinking about what underlies children's responses on this task, one possibility is that young children's beliefs that categories mark what their members are supposed to do is grounded in their particular expectations about human social structures-that is, their domainspecific understanding of what motivates and constrains human social behavior in groups. Children's early understanding of the prescriptive force of group membership could arise from their own social interactions (Piaget, 1932; Rakoczy \& Schmidt, 2013; Rakoczy et al., 2008; Rutland et al., 2010; Searle, 1995; Smetana, 1981; Tomasello, 2019a; 2019b). For example, Tomasello (2019a; 2019b) proposes that children's understanding of prescriptive social norms develops first through their own experiences of shared agency in the context of collaboration with social partners (e.g., an understanding that they themselves and another person have committed to doing something together, which then obligates each of them to follow through on 
the shared goal), which they then later generalize outward to construct a more general abstract sense of prescriptive norms across whole groups (e.g., that entire groups of people can be obligated to do certain things together-an abstract understanding of collective intentionality thought to emerge around age 3; Tomasello, 2019a; 2019b; see also, Rakoczy and Schmidt, 2013). From this perspective, children's intuition that social categories prescribe how their members ought to behave reflects their abstract understanding of the nature of collective intentionality - a fundamental component of how they understand and navigate the social world and their own social relationships.

This possibility is consistent with approaches to conceptual development that describe category representations as embedded in domain-specific intuitive theories-in this case, that children have abstract expectations that social categories mark people who share the same social obligations (Kalish \& Lawson, 2008; Rhodes, 2013). In contrast, intuitive theories of artifact categories might instead highlight expectations of shared function, and intuitive theories of animal categories might be shaped by expectations of shared intrinsic, biological properties (Gelman \& Kalish, 2007). From this perspective, domain-specific abstract expectations shape how children acquire categories in each domain and how they then use those categories to guide their learning and reasoning about the world. On this account, children's tendency to assume that people must follow the norms of their social groups (e.g., that they must eat the foods that other people in their group eat), even when they do not know anything about the groups and have not heard any explicitly normative information (as documented by Roberts, Gelman, \& Ho, 2017a), reflects their domain-specific expectations that social categories mark people who share the same obligations. If so, this kind of descriptive-to-prescriptive reasoning about category regularities would be specific to their reasoning about categories of people, not a more general feature of early category-representations.

\section{Prescriptive Judgments About Categories in Other Domains}


Broadly, the idea that prescriptive reasoning emerges from processes unique to the social domain is consistent with general findings of domain differences in early category structure (Gelman \& Noles, 2011; Rhodes \& Gelman, 2009). For instance, whereas children view social categories as both descriptive and prescriptive about what people ought to do (Kalish \& Lawson, 2008; Roberts et al. 2017a; Rhodes \& Chalik, 2013), basic-level animal categories, for example, often appear to serve a simply descriptive function, allowing children to build up knowledge of the world by generalizing what they learn about one category member (e.g., a particular dog) to other members of the category (e.g., dogs in general).

This is not to say that there is no overlap in how children think about categories of people and those of other animals. For example, children understand humans as a biological category, and sometimes think of humans as one type of animal out of many (Carey, 1985; Herrmann et al., 2010; Medin et al., 2010). Conversely, children sometimes think of some human social categories (e.g., gender, race) as grounded in biological differences (Hirschfeld, 1995; Taylor, Rhodes \& Gelman, 2009). Also, children sometimes represent non-human animals as social agents that engage in shared social behaviors (Bloom, 2007; Guthrie, 1993; Piaget, 1929). Yet, despite these similarities in how children represent and use categories of people and other animals, there are some striking domain differences as well. For example, children expect animal categories to reflect objectively true biological distinctions in nature, but they expect many human social categories to be more flexible and subjective (Rhodes, Gelman, \& Karuza, 2014; Rhodes \& Gelman, 2009). Similarly, when children are first introduced to new, labeled animal categories, they expect those categories to be stable over time, whereas more input is required for them to think of a newly learned social category in this way (Diesendruck \& Deblinger-Tangi, 2014). Children also expect animal categories to be more homogeneous than categories of people (Brandone, 2017; Rhodes \& Moty, 2020): They readily extend features (including biological, behavioral, and psychological) features from one animal to other members of its category, but they make much more limited inferences about the shared features of human 
social categories (often assuming, particularly as they are just learning about new social categories, that members of a human social category share obligations but not other features, as reviewed above). Further, representations of animal categories show more consistency across different kinds of animals, as well as across development and diverse cultural contexts (Medin \& Atran, 2004), whereas representations of social categories are more variable across individuals, developmental and historical time, and cultures (Hirschfeld, 1996). These patterns of domain differences in the nature of category representations further illustrate how children's concepts are embedded in abstract intuitive theories about different domains of experience (Gelman \& Kalish, 2007). From this perspective, and given that prescriptive expectations seem particularly central to young children's early social reasoning, it would be unsurprising if the type of descriptive-to-prescriptive reasoning documented by Roberts and colleagues is specific to children's reasoning about human social categories and does not extend across domains, even to animal categories, despite the areas of conceptual overlap across biological and social kinds.

Yet on the other hand, signatures of a heightened prescriptive focus also emerge in several aspects of children's biological thought. For instance, young children (ages 4-7), as well as adults, hold prescriptive expectations about characteristic properties of animals (e.g., they think that dogs should bark, have four legs, etc., and that there is something wrong with a dog that does not; Haward et al., 2018; Prasada \& Dillingham, 2006; 2009). Also, young children (ages 5-10) and adults hold idealized views of what animals are supposed to be like, viewing members of animal categories that show the most extreme values of characteristic features (e.g., the giraffe with the very longest neck) as the "best" of their kinds (Foster-Hanson \& Rhodes, 2019a). These instances of apparent prescriptive reasoning regarding animals raise the possibility that prescriptive expectations about categories could reflect more general features of conceptual structure, rather than only children's specific intuitions about the nature of human social interaction. For instance, perhaps children have a more general expectation that categories mark not only how category members are but also the way they are supposed to 
be-an expectation that then manifests in children's representations and use of categories across domains. From this perspective, children's descriptive-to-prescriptive reasoning about categories of people may be a particular manifestation of a more general feature of early conceptual representations.

As in the social domain, prescriptive reasoning in the biological domain appears to be particularly prominent in early childhood and to decline across childhood into adulthood. For example, children have been described as "promiscuously teleological," in that they readily explain both living and nonliving natural entities as existing in order to fulfill a functional purpose (e.g., reasoning that giraffes have long necks so that they can eat the leaves on tall trees; Kelemen, 1999), whereas adults appeal to these explanations more selectively (Atran, 1994; Kelemen \& Rosset, 2009; Kelemen et al., 2013; Lombrozo et al., 2007; Sánchez Tapia et al., 2016; Ware \& Gelman, 2014). Although teleological reasoning might not always be quite the same as thinking prescriptively_thinking that giraffes have long necks so that they can eat leaves up high is not the same as thinking they are supposed to have long necks-these ideas often seem to be conflated in children's thought. For instance, children ages 6-9 think that natural entities that can no longer fulfill their teleological functions should be fixed or replaced (DiYanni \& Kelemen, 2005). Also, not only do young children think that the giraffe with the very longest neck is the "best" of its category, they also think this "very tallest giraffe" is the most representative of what giraffes are really like, and provides the most generalizable information about other giraffes (Foster-Hanson \& Rhodes, 2019a; Foster-Hanson et al., 2020). In contrast, while adults in this work judged the "very tallest giraffe" as the best of its category, they viewed the more average-height giraffe as representative and informative; this transition in children's thinking was observed gradually across childhood from ages 5 through 10 . Thus, young children's biological categories appear to be structured around idealized prototypes-ideas about how giraffes are supposed to be-with relatively little regard for real within-category variation. Consistent with this interpretation, children generally have narrower prototypes than 
adults (Mervis \& Pani, 1980), often excluding atypical members, and they tend to have more homogeneous views of animal categories, neglecting variation (Emmons \& Kelemen, 2015; Shtulman \& Schulz, 2008). From this perspective, across childhood and into adulthood, children develop more expansive and variable category representations, which may be reflected in their category judgments across domains.

Like domain-specific proposals about the origins of prescriptive reasoning in the social domain, some have proposed that prescriptive teleological reasoning about the natural world arises as a result of particular cognitive adaptations for biological reasoning (e.g., Atran, 1994; Keil, 1992). On the other hand, others (e.g., Kelemen, 2004) have proposed that children's early propensity to reason about biological categories through a prescriptive lens might be a byproduct of a socially intelligent mind that is naturally inclined to attribute goals to agents, and therefore to explain the natural world as the result of intentional design (see also Evans, 2001). Under this proposal, prescriptive reasoning could underlie category representations more generally.

Despite decades of research examining and comparing the development of social categories and biological concepts, the development of prescriptive reasoning has rarely been directly compared across domains, and very different paradigms have been used to assess prescriptive reasoning about animal and human social categories. For example, children's prescriptive reasoning regarding animals has usually been studied by asking about their beliefs about highly familiar animals and their features (e.g., their beliefs that giraffes should have long necks, that dogs should bark, and so on). Thus, it is possible that the normative component of their beliefs about animal categories arises quite differently than for human social categoriesas a consequence of, rather than as a precursor to, acquiring category knowledge. For instance, rather than reflecting a basic intuition that animal categories are supposed to share features, children could develop the idea that giraffes should have long necks slowly over time, from seeing this feature of giraffes expressed in language and emphasized repeatedly across 
contexts. To compare whether the mechanisms underlying normative reasoning are similar for categories of animals and people, it is thus necessary to test if such reasoning emerges under similar conditions across domains.

\section{The present studies}

In the present studies, we directly compare prescriptive judgments about novel social categories—amply demonstrated in prior research—with prescriptive judgments about novel animal categories, with the stimuli and procedures matched as closely as possible across category domains. We focused on novel categories, as in Roberts and colleagues (2017a), to test whether prescriptive reasoning emerges when children have limited information, with no exposure to prior category knowledge or normative language. Using this direct comparison, we test whether children's early focus on the prescriptive force of categories arises not only for categories of people, but across conceptual domains to shape their representations of animal categories as well. We selected animal categories as a critical first test case because the comparison between people and animals builds on and contributes to the body of prior work examining domain-specificity in conceptual structure across these two domains (Gelman \& Noles, 2011; Rhodes \& Gelman, 2009), and because a key goal was to consider whether instances of prescriptive reasoning about animal categories and human social categories that have been documented in prior work might reflect similar cognitive origins. We discuss the implications of this comparison for category representations in other domains in the General Discussion.

In addition to considering whether prescriptive reasoning about category features arises under similar conditions in childhood across domains, we also consider how the developmental trajectory of such prescriptive reasoning might vary across domains. As noted earlier, in the social domain, prescriptive reasoning appears to relax across development-adults are often more approving of social nonconformity than are young children, at least when reasoning about novel categories. One possibility is that we will find a similar age-related trajectory in the 
biological domain. Although adults sometimes think about the biological world through a prescriptive lens, particularly when they are focused on the adaptive fitness value of categorybased features (Foster-Hanson \& Rhodes, 2019a) or their own goals for interacting with members of the category (Barsalou, 1985; Burnett et al., 2005; Lynch et al., 2000), they appear to do so less often and less robustly than children, often relying instead on more descriptive information (Kim \& Murphy, 2011; Osherson et al., 1990; Shtulman \& Harrington, 2016). Yet, the extent to which adults show prescriptive reasoning in the biological domain also appears to vary with their own category knowledge and level of expertise (Burnett et al., 2005; Lynch et al., 2000). Therefore, to directly compare prescriptive reasoning across domains and development, we included children ages 4-9 (the age range that has shown gradual transitions in both biological and social reasoning in prior work) and adults.

We also compare the evidence necessary to generate prescriptive judgments across domains, by presenting animals and people either in groups (e.g., a group of Hibbles) or as individuals (e.g., a single person or animal). In previous work, children formed prescriptive expectations about novel social categories only after learning that multiple category members displayed the property (Roberts et al., 2017a, 2017b). Although this could be the case for animal categories as well, we also considered the possibility that children's judgments might interact with their domain-specific beliefs about category structure (e.g., their expectations that animal categories are generally more homogeneous). Thus, the current studies examined prescriptive judgments of novel biological and social categories in children ages 4-9 and adults together, using the paradigm developed by Roberts et al. (2017a). In Study 1, we examined the domaingenerality of early prescriptive reasoning, using the same stimuli used in Roberts et al. (2017a) and novel animal stimuli. In Study 2, we tested the robustness of patterns of early prescriptive judgments of biological and social kinds while holding visual cues constant across domains.

\section{Study 1}

\section{Method}


Participants. Child participants were 1064 - to 6-year-olds ( $M$ age $=5.44 ; 64$ female and 42 male) and 103 7- to 9-year-olds ( $M$ age $=8.29 ; 54$ female and 44 male, 5 unreported). We included these age groups to directly align the current studies with previous work, including studies using this paradigm (Roberts et al., 2017a). We planned to recruit 24 participants in each age group per condition, following conventions in the lab. We stopped testing on the day we reached those numbers. Another 6 children were tested but excluded from analysis at the time of testing (1 because of significant interruptions, 1 because of technical difficulties, and 4 because they chose not to complete the study). Of our sample of children whose parents provided demographic information (12\% chose not to report this information), $67 \%$ were White, $9 \%$ were Black, $16 \%$ were Asian, $7 \%$ were more than one race; $27 \%$ were Hispanic (of any race). Children were recruited and tested at two museum testing locations in a large northeastern city in the U.S., as well as in local public pre-K centers and a public school aftercare program. Children gave oral consent and their parents provided written consent.

Adult participants $(N=135, M$ age $=35.07 ; 58$ female and 77 male $)$ were recruited using Amazon Mechanical Turk and tested using Qualtrics. We included two attention check questions in this study, which all participants answered correctly; therefore, all adults were included in the analysis. All adults provided demographic information: $83 \%$ were White, $6 \%$ were Black, $7 \%$ were Asian, $1 \%$ were Native American or Alaskan Native, and $3 \%$ were more than one race; $10 \%$ were Hispanic. Adults provided written consent. All participants spoke English as their primary language, and all study procedures were approved by the Institutional Review Board of the last author's university.

Materials. For data, analysis, and full procedure, see https://osf.io/cbf59/. Materials were based on those used by Roberts et al. (2017a). To present categories of people, participants were shown cartoon illustrations of people wearing two different colors of clothing, from previous work. We chose to use categories of people who varied only in clothing color in order to avoid presenting participants with visual cues that might map onto familiar categories such as race, as 
well as to facilitate comparison with previous work. To present animal categories, we created similar illustrations of two novel animal kinds (Figure 1). Participants made judgments about four properties: two from previous work that were deemed suitable for queries about both animals and people (food choice, toy choice; Roberts et al., 2017a), and two additional properties created to fit this criterion (food storage, sleeping location). In pretests with adults $(N=57)$, all four properties were judged as choice-based, rather than biologically determined, equally for people and animals (for pretest data and analyses see: https://osf.io/cbf59/).

Procedure. Participants were randomly assigned to one of four conditions, in a 2 (domain: Animals, People) x 2 (scope: Group, Individual) design. Each participant saw either animals or people, presented either in groups or individually. All participants saw conforming and nonconforming trials for each behavior split into two different blocks, with each block containing two conforming and two nonconforming trials. Block order and the location of individuals/groups on the screen were counterbalanced between participants.

Participants were first introduced to two individuals or groups. In Group conditions, each was given a novel label (e.g., "Look at these animals, they're called Hibbles! Now look at these animals, they're called Glerks!"). In Individual conditions, people and animals were presented with no label (e.g., "Look at this one!"). On each trial, the groups/individuals were then described as displaying different behaviors of the same type (e.g., "Hibbles eat this [yellow] kind of berry, and Glerks eat this [orange] kind of berry"), shown on either side of the screen. In all conditions, another individual, the same color as one of the two groups/individuals already presented, was then shown in the middle of the screen and described as displaying either the same behavior as its kind (conforming, e.g., "Look, this Glerk is eating this [orange] kind of berry") or a different behavior from its kind (nonconforming, e.g., "Look, this Glerk is eating this [yellow] kind of berry"). Participants then made a prescriptive judgment about the behavior (e.g., "Is it OK or not OK for this Glerk to eat this kind of berry?"). Participants who answered that the behavior was "not OK" rated the degree of severity on a 3-point scale (e.g., "How bad was it? A little bad, 
pretty bad, or very, very bad?"). Lastly, all participants were asked to explain their answer regardless of initial response (e.g., "Why is it not OK for this Glerk to eat this kind of berry?"; explanation data are available at https://osf.io/cbf59/).

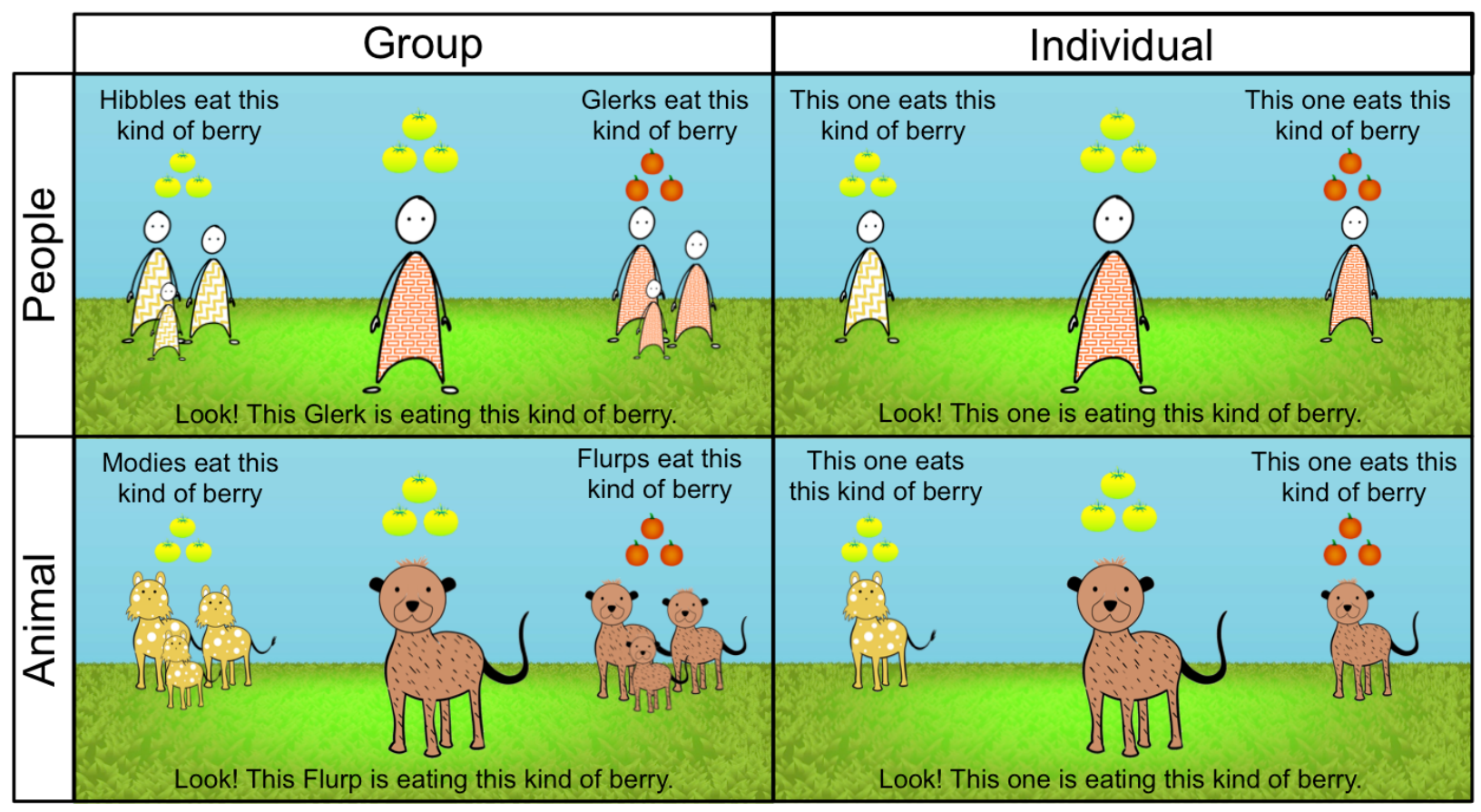

Figure 1

Sample trial materials by condition, Study 1. Participants were randomly assigned to see either animals or people, presented either in groups or as individuals. Pictured examples are from nonconforming trials.

\section{Results}

Binary "OK" Responses. Our primary dependent variable was participants' initial binary "OK" or "not OK" judgments. We analyzed these responses using a Generalized Linear MixedEffect Model (GLMM) with the Ime4 package (Bates et al., 2015). We included age categorically in order to compare children's judgments to those of adults in our analyses. We used the "glmer" function to specify a binomial distribution and tested as predictors the main and interactive effects of age group (children ages 4-6, children ages 7-9, adults), domain (Animals, People), scope (Group, Individual), and conformity (Conforming, Nonconforming). We also analyzed children's data separately, including their exact age as a continuous variable. We included random intercepts for each item, participant, counterbalancing order, and testing site. 
For all measures, we report the results of Likelihood Ratio Tests, comparing models with and without the factor of interest. All data were analyzed using $R$ version 4.0.2. Data and analysis code are available at https://osf.io/cbf59/.

Overall, these analyses revealed a number of effects, all subsumed by a four-way interaction among age, domain, group, and conformity $\left(X^{2}(2)=6.36, p=.04\right)$. As expected, participants rarely disapproved of conformity $(M=0.03,95 \% \mathrm{Cl}[0.01,0.05])$, although younger children were slightly more likely to do so, suggesting that a small number of them may have found the task too challenging or responded based on other factors (see the Supplementary Online Material). Our full model (with item included as a factor to allow for comparison) differed significantly from a reduced model containing only control variables $\left(X^{2}(23)=1321.16, p<\right.$ .001). To facilitate interpretation of our main theoretical questions (evaluations of nonconformity), we focused on the nonconforming trials and conducted two sets of follow-up analyses testing for the effects of age and domain, separately for Group conditions and Individual conditions.

For Group conditions, disapproval of nonconformity declined with age $\left(X^{2}(2)=15.88, p\right.$ $<.001)$, with no main $\left(X^{2}(1)=1.11, p=.29\right)$ or interactive $\left(X^{2}(2)=0.65, p=.72\right)$ effects of domain. Children (of both age groups) disapproved of nonconformity to groups more than adults did. When children's data were analyzed separately, with age included continuously, there were no significant main or interactive effects (all ps > .1). As illustrated in Figure 2, participants of all ages responded very similarly to categories of people and animals.

In contrast, for judgments of nonconformity among individuals, the effect of age varied by domain $\left(X^{2}(2)=7.08, p=.03\right)$. Children (of both ages) generally disapproved of nonconformity among individual animals but generally accepted nonconformity among individual people (pairwise comparison, ages 4-6: $p=.003$; ages 7-9: $p=.02$ ), whereas adults were more accepting of nonconformity among individual animals and individual people. Indeed, children (of 
both ages) disapproved just as often of nonconformity among individual animals and groups of animals (ages 4-6: $p=1$; ages 7-9; $p=.73$ ), but in judgments of people, they were more disapproving of nonconformity to groups than individuals (ages 4-6: $p=.004$; ages 7-9: $p=$ .005). When children's data were analyzed separately, with age included continuously, only the main effect of domain was significant $\left(X^{2}(1)=27.99, p<.001\right.$; all other $\left.p s>.1\right)$.

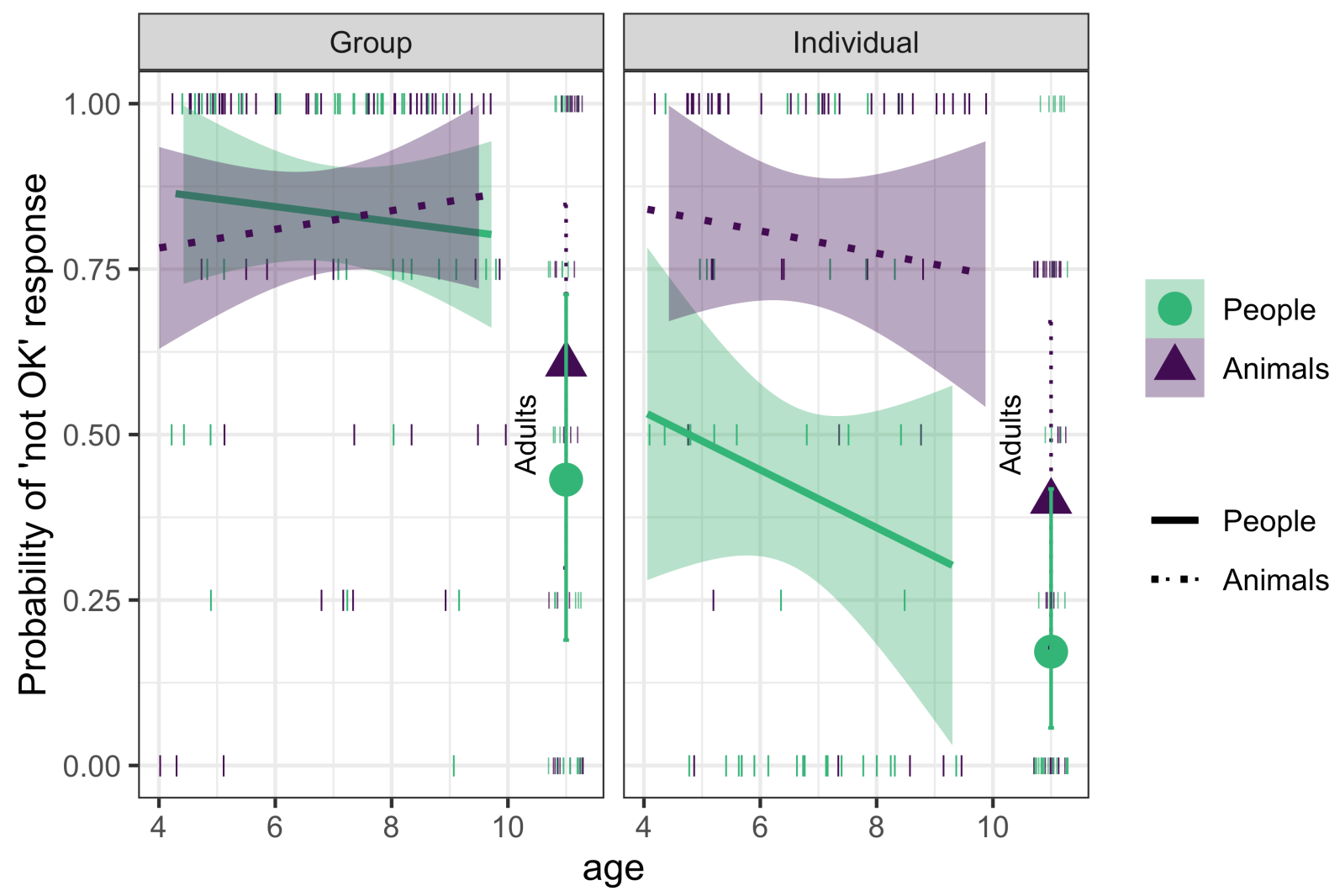

Figure 2

Probability of "not OK" responses by age, domain, and scope; nonconforming trials only, in Study 1. Children are included with age as a continuous variable, with shaded areas showing Wald 95\% Confidence Intervals, and small lines show the proportion of "not OK" responses for individual participants. The solid lines show the People conditions and the dotted lines show the Animal conditions. Adults are included with age as a categorical variable, large shapes show condition means and error bars show Wald 95\% Confidence Intervals. Higher values represent more "not OK" responses.

Scale Responses. We examined responses to the follow-up question "How bad was it?" (scored: 1 = "A little bad," 2 = "Pretty bad," 3 = "Very, very bad," asked only after participants gave "not OK" responses to the initial question), using an ordinal logistic regression with the Ordinal package (Christensen, 2019). We first included age categorically in order to compare 
judgments of children and adults, as in analyses of binary "OK" responses. This analysis revealed only a significant main effect of age group $\left(X^{2}(2)=19.02, p<.001\right)$, with 4 - to 6-yearolds $(M=2.40,95 \% \mathrm{Cl}[2.31,2.49])$ giving more negative responses than 7 - to 9 -year-olds $(M=$ 2.11, 95\% Cl $[2.02,2.21]$; pairwise comparison, $p<.001)$, and adults giving the least negative responses $(M=1.77,95 \% \mathrm{CI}[1.67,1.87]$; pairwise comparison, $p<.001)$. Only the main effect of age was significant when children's data were analyzed separately, with age included continuously $\left(X^{2}(1)=9.94, p=.002\right)$.

\section{Discussion}

The results of Study 1 suggest that children hold prescriptive expectations for both social and non-social (animal) categories, and that the strength of these expectations decreases with age. Children said it was wrong for a category member to engage in category-atypical behavior at very similar levels across domains, consistent with the possibility that this form of prescriptive reasoning reflects mechanisms that cross domain boundaries.

The evidence required to generate these beliefs differed across domains, however-for social categories, children required direct evidence of group homogeneity (multiple category members displaying the property), whereas for animal kinds, even a single category member was sufficient. Whereas the data from Study 1 clearly support the hypothesis that children's prescriptive expectations of categories constraining behavior reflect more general features of conceptual structure, they do not resolve whether these beliefs are activated differently across domains.

One possible explanation for this asymmetrical activation is that visual cues to kind membership differed between the two domains. Whereas people differed only in clothing color, which alone does not mark category boundaries (e.g., Baldwin, 1989), animals differed in fur color and physical features such as tail shape, ear shape, etc. These visual cues could have been sufficient to lead children to think of the two animals as representatives of different species even in the Individual condition, whereas for social categories, perhaps children did not see the 
individuals as representatives of distinct kinds (viewing them just as two people who happened to be wearing different color clothes). Indeed, in everyday life, it is often straightforward to determine whether two animals are members of different basic-level categories based solely on perceptual cues, but for many social categories it may be more difficult to determine if people are members of different groups based on perceptual cues alone. For social categories, other cultural cues, such as strong linguistic cues, may be needed (e.g., generic generalizations about categories; Rhodes et al., 2018). Indeed, even children's beliefs about social categories linked to visual cues such as skin color emerge gradually throughout childhood and vary depending on cultural experience (Mandalaywala et al., 2019; Rhodes \& Gelman, 2009; Segall et al., 2014, but see Dunham et al., 2014).

Alternatively, perhaps children recognized the individuals as representing distinct categories in both domains but thought the behavior of a single animal—and not a single person-was sufficient to indicate what category members usually (and therefore should) do. In this way, children's prescriptive judgments might differ across domains depending on what it takes to recognize individuals as members of distinct kinds, or what it takes to view a behavior as constrained by category-based norms. To tease apart these possibilities, in Study 2 we held visual cues to kind membership constant across domains.

Prescriptive judgments likely serve different functions for social and biological categories-whereas prescriptive reasoning about social groups might help children to regulate their own and others' behavior (Rakoczy \& Schmidt, 2013; Tomasello, 2019a; 2019b), prescriptive reasoning about non-social categories like animals would not serve the same function. For this reason, in Study 2 we also explored people's intuitions about the consequences of nonconformity across the social and biological domains.

\section{Study 2}

\section{Method}


We pre-registered the hypotheses, design, and analysis code for Study 2 prior to data collection (https://osf.io/cbf59/). We predicted that, consistent with Study 1, children would negatively evaluate category-atypical behaviors involving groups of animals and people, and that the strength of these evaluations would decline with age. For the Individual conditions, we laid out two possible patterns and how we would interpret them in our preregistration plan. If children still disapproved more of nonconformity in individual animals than individual people, as in Study 1, even with visual cues to category membership held constant, this would indicate that children treat the behavior of a single animal as indicating what all members of an animal species are supposed to do, but that direct evidence of multiple people doing a behavior is needed to support this inference for social categories. But on the other hand, if these domain differences were eliminated now that visual cues to categories were held constant across domains, this would indicate that the domain differences observed in Study 1 reflected differences in the extent to which children recognized individuals as members of distinct kinds based on the perceptual information available. We planned to recruit a total of 220 adults and 220 4- to 6-year-old children in Study 2, based on power analysis of the domain x scope interaction in Study 1 (because this was the effect Study 2 was primarily designed to test). We included only the younger age group (4- to 6-year-olds) and adults in Study 2 as a strong test of our hypothesis, because children in this age group were the most disapproving of nonconformity in individual animals.

Participants. Of our recruited 220 child participants, following our pre-registered exclusion criteria, 3 children were excluded because of significant interruptions during testing or parent interference, or because they did not complete the study, leaving 2174 - to 6-year-old children $\left(M_{\text {age }}=5.41 ; 118\right.$ female and 99 male $)$. Of our sample of children whose parents reported demographic information ( $8 \%$ did not), $66 \%$ were White, $5 \%$ were Black, $18 \%$ were Asian, and $8 \%$ were more than one race; of these, $9 \%$ were Hispanic (of any race). Children were recruited and tested at a museum testing site in a large northeastern city in the U.S. 
Children gave oral consent and their parents provided written consent.

Of our recruited 220 adults, 2 were excluded for not completing the study, and 22 incorrectly answered more than one "Winograd" question designed to confirm that participants were human and to exclude bots (as per our pre-registration; Levesque et al., 2012 ${ }^{1}$ ). This left 186 adult participants $\left(M_{\text {age }}=34.40 ; 71\right.$ female and 114 male, 1 preferred not to answer), recruited using Amazon Mechanical Turk and tested using Qualtrics. All adults provided demographic information: $80 \%$ were White, $6 \%$ were Black, $8 \%$ were Asian, $1 \%$ were Native American or Alaskan Native, and $2 \%$ were more than one race; $10 \%$ were Hispanic (of any race). Most (49\%) were from suburban areas across the U.S.; $35 \%$ were from urban areas and $16 \%$ were from rural areas. Adults provided written consent. All participants spoke English as their primary language, and all study procedures were approved by the Institutional Review Board of the last author's university.

Materials. As in Study 1, participants were randomly assigned to hear about either two novel animal kinds or two novel social kinds, each presented either as groups or as individuals. However, in both domains, participants were told that the animals or people in question were hiding behind different colored doors, thus allowing participants to see identical stimuli, with the same cues to category membership, across both domains. For Group conditions, participants saw three doors (similar to the three animals or people shown in Group conditions in Study 1), and in Individual conditions participants saw single doors.

Procedure. First, to help children bring to mind the idea of categories of animals or people (since they did not see any visual examples during the main experiment), participants were shown a photograph collage of either people or mammals and were told, "Today we're going to play a game about animals/people! Look at all these different kinds of animals/people." All visual stimuli throughout the remainder of the study were identical across domains.

\footnotetext{
${ }^{1}$ In a single deviation from our pre-registration, we chose to ask these questions at the end of the study instead of at the beginning.
} 
Participants were then introduced to two groups or two individuals, hiding behind different colored doors. We based this design on several previously published papers that successfully used this "hiding behind doors" method with young children (Gelman et al., 1998; Rhodes, Gelman, \& Karuza, 2014; Roberts \& Gelman, 2015). In Group conditions, each was given a label as in Study 1 (e.g., "The animals/people hiding behind these yellow doors are called Hibbles. Hibbles always hide behind yellow doors."). In the Individual conditions, animals and people were presented with no label, but were described as "kinds" (e.g., "There's one kind of animal/person hiding behind this yellow door. This kind of animal/person always hides behind yellow doors."). We included this description in the Individual conditions in order to convey that the individuals differed from each other, which would not have otherwise been apparent. This allowed us to further disambiguate between the effects of beliefs that individuals represented distinct kinds, different perceptual cues to kind membership, and seeing properties as regularities among groups in shaping people's expectations of conformity. Children completed a manipulation check, by pointing to the correct locations of each category or individual, to ensure they understood the procedure before moving on.

On each trial, the groups/individuals were then described as displaying conforming or nonconforming behaviors, as in Study 1 (e.g., Group: "Hibbles eat this [yellow] kind of berry, and Glerks eat this [orange] kind of berry"; Individual: "The animal/person behind this yellow door eats this [yellow] kind of berry, and the animal/person behind this orange door eat this [orange] kind of berry"). Another individual, behind the same color door as one of the two groups/individuals already presented, was then described as displaying either the same behavior as its kind (conforming, e.g., "Look, this Glerk is eating this [orange] kind of berry") or a nonconforming behavior (e.g., "Look, this Glerk is eating this [yellow] kind of berry"). Participants made a judgment about the behavior (e.g., "Is it OK or not OK for this Glerk to eat this kind of berry?"; Figure 3). 


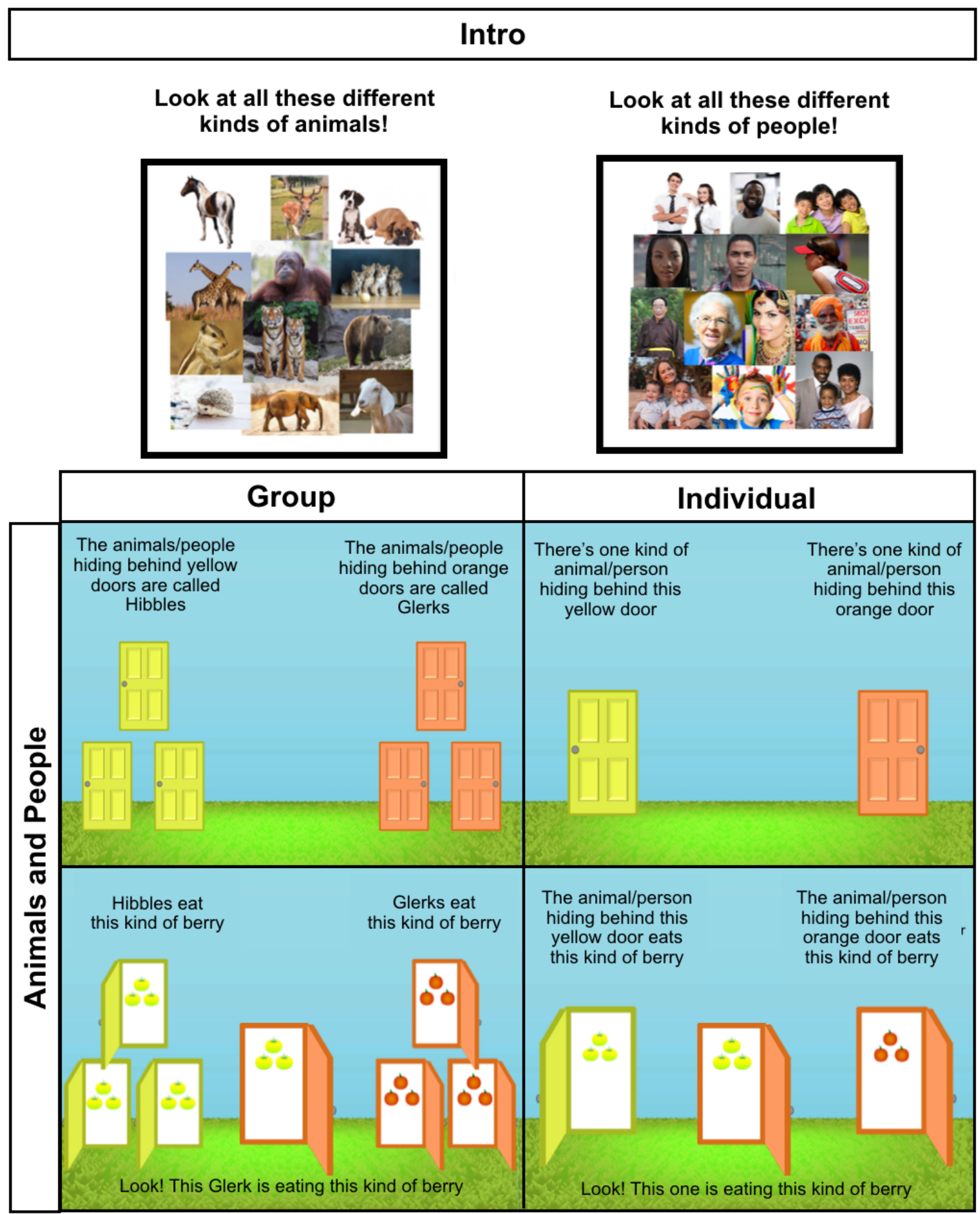

Figure 3

Sample trial materials by condition, Study 2. Participants were randomly assigned to hear about either animals or people, presented either in groups or as individuals, hiding behind different colored doors. They first saw a collage of images from the assigned domain. The remainder of the images they saw throughout the study were identical across domains. Pictured examples 
are from nonconforming trials.

On each nonconforming trial, participants were also asked to predict the consequences of nonconformity. We included these measures in Study 2 to explore possible differences in the nature of prescriptive judgments across age and domain. These questions were designed to test slightly different aspects of children's and adults' judgments, so the procedure for these measures varied slightly between age groups. Children were asked to choose either (a) a functional consequence for the nonconforming individual (e.g., "It will get a tummy ache"), (b) a social consequence (e.g., "The other Hibbles will be mad"; presented in counterbalanced order), or (c) an open-ended consequence (e.g., "Something else will happen"). Children who selected "something else" were asked to provide an explanation, which was written down by the experimenter and later coded by another trained researcher (see the SOM).

For adult participants, we expected relatively few "not OK" responses on nonconforming trials; therefore, adults were first asked whether something bad would happen, or whether nothing bad would happen. If they responded that something bad would happen, they were then asked to select between a functional consequence for the nonconforming individual or a social consequence, like child participants. If they responded that nothing bad would happen, they were asked to choose between two explanations for their approval: (a) individual freedom (e.g., "It can eat whatever berry it wants"), or (b) variation (e.g., "People eat lots of different kinds of berries"). All answer pairs were presented to adults in randomized order.

\section{Results}

Binary "OK" Responses. Our primary dependent variable was participants' initial binary "OK" or "not OK" judgments; we analyzed these responses as in Study 1. Our analyses revealed a number of effects, all subsumed by three-way interactions among age, domain, and conformity $\left(X^{2}(2)=9.17, p=.01\right)$, and among age, scope, and conformity $\left(X^{2}(2)=7.42, p=\right.$ .03). Children disapproved more of nonconformity in groups $(M=0.87,95 \% \mathrm{Cl}[0.81,0.92])$ than in individuals $(M=0.61,95 \% \mathrm{Cl}[0.50,0.70]$; pairwise comparison, $p<.001)$, whereas 
adults disapproved of nonconforming groups $(M=0.66,95 \% \mathrm{Cl}[0.55,0.76])$ and individuals at similar levels $(M=0.52,95 \% \mathrm{Cl}[0.40,0.64]$; pairwise comparison, $p=.67)$. Participants again rarely disapproved of conformity $(M=0.03,95 \% \mathrm{Cl}[0.02,0.04])$. The four-way age $\mathrm{x}$ conformity $x$ domain $x$ scope interaction was not significant $\left(X^{2}(1)=2.51, p=.11\right)$, nor were any other three-way interactions. Our full model (with item included as a factor to allow for comparison) differed significantly from a reduced model containing only control variables $\left(X^{2}(15)=1462.67\right.$, $p<.001)$. As in Study 1, and per our pre-registered analysis plan, we focused on the nonconforming trials and conducted two sets of follow-up analyses testing for the effects of age and domain, separately for Group conditions and Individual conditions, to facilitate interpretation of our theoretical questions (evaluations of nonconformity).

Consistent with Study 1 and our pre-registered hypothesis, children's disapproval of nonconformity in groups of people $(M=0.97,95 \% \mathrm{Cl}[0.92,0.99])$ and groups of animals $(M=$ $0.87,95 \% \mathrm{Cl}[0.70,0.95])$ did not differ significantly (pairwise comparison, $p=.08$ ). Children again disapproved of nonconformity in groups of people more than adults did $(M=0.52,95 \% \mathrm{Cl}$ $[0.26,0.76] ; p<.001$ ). However, unlike in Study 1 (and contrary to our preregistered hypothesis), adults disapproved of nonconformity in groups of animals similarly to children $(M=$ $0.85,95 \% \mathrm{Cl}[0.66,0.95]$; age $\mathrm{x}$ domain interaction, $X^{2}(1)=11.38, p<.001$; subsumed main effect of age, $\left.X^{2}(1)=11.13, p<.001\right)$.

For evaluations of individuals, disapproval of nonconformity showed no significant main effects (age, $X^{2}(1)=1.06, p=.30$; domain, $\left.X^{2}(1)=1.02, p=.31\right)$ and the age $\mathrm{x}$ domain interaction was not significant $\left(X^{2}(1)=3.09, p=.08\right)$. Overall, participants sometimes disapproved of nonconformity in individuals (children: $M=0.70,95 \% \mathrm{Cl}[0.52,0.83]$; adults: $M=$ $0.56,95 \% \mathrm{Cl}[0.36,0.74])$, but these responses were less frequent overall than in Group conditions. Thus, when children saw the same visual cues to category membership across domains, they expected members of both animal and social categories to conform to their 
groups; they also sometimes expected conformity among individual animals or people, though not to the same extent.

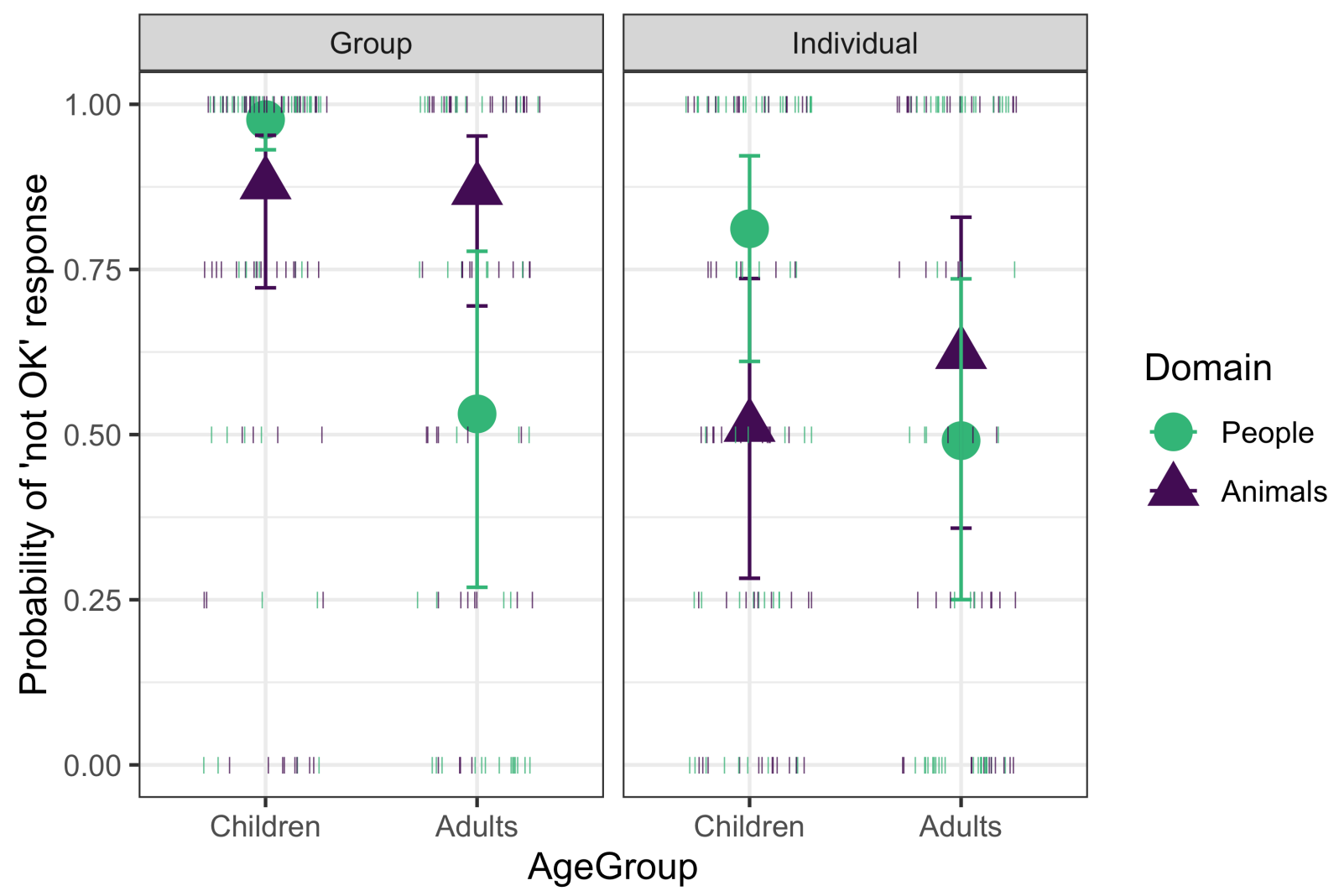

Figure 4

Probability of "not OK" responses by age group, domain, and scope; nonconforming trials only, in Study 2. Higher values represent more "not OK" responses. Large shapes represent cell means with Wald 95\% Confidence Intervals, small lines show the proportion of "not OK" responses for individual participants.

Consequences of nonconformity. After all nonconforming trials, we asked participants to predict the consequences of nonconformity. We did not have strong a priori predictions about participants' predicted consequences of nonconformity, so our analyses of these measures were planned but exploratory. The procedure for adults and children varied, so we planned to analyze these measures separately for children and adults.

Children's predicted consequences of nonconformity. We analyzed children's predictions as the probability of choosing each theoretically relevant response type (functional harm, social harm) using Generalized Linear Mixed-effect Models. Children were more likely to 
predict functional harm (e.g., "It will get a tummy ache") for animals $(M=0.43,95 \% \mathrm{Cl}[0.35$, $0.51])$ than for people $\left(M=0.33,95 \% \mathrm{Cl}[0.26,0.40]\right.$; main effect of domain, $X^{2}(1)=5.97, p=$ .02). These choices did not vary by scope (domain $x$ scope interaction, $X^{2}(1)=3.24, p=.07$ ). Predictions of social harm (e.g., "The other Hibbles will be mad") did not vary by domain or scope $(M=0.24,95 \% \mathrm{Cl}[0.21,0.27])$.

Adults' predicted consequences of nonconformity. We queried adults' beliefs using a series of binary questions, and we analyzed responses to each question (for the subset of participants who were asked each) using Generalized Linear Mixed-effect Models. When asked whether "something bad" or "nothing bad" would happen as a result of nonconformity, adults predicted that nonconformity would result in "something bad" for animals $(M=0.29,95 \% \mathrm{Cl}$ $[0.10,0.61])$ more than for people, for whom they rarely predicted negative consequences $(M=$ $0.09,95 \% \mathrm{Cl}[0.02,0.29]$; main effect of domain, $\left.X^{2}(1)=6.80, p=.009\right)$, with no main $\left(X^{2}(1)=\right.$ $0.93, p=.34)$ or interactive $\left(X^{2}(1)=0.02, p=.88\right)$ effects of scope). When they did predict negative consequences, they thought those consequences would be functional more often than social (probability of predicting social harm, $M=0.34,95 \% \mathrm{Cl}[0.29,0.40]$ ), regardless of domain $\left(X^{2}(1)=0.50, p=.48\right)$ or scope $\left(X^{2}(1)=1.40, p=.24 ;\right.$ domain $x$ scope interaction, $X^{2}$ (1) $=0.11, p=.74)$.

When adults predicted that nothing bad would happen, however, they explained their approval by appealing to variability (e.g., "People eat lots of different kinds of berries") more often in Individual conditions $(M=0.57,95 \% \mathrm{Cl}[0.41,0.71])$ than in Group conditions $(M=0.03$, $95 \% \mathrm{Cl}[0.01,0.09])$, in which they almost always appealed to individual choice (e.g., "It can choose to eat whatever berry it wants;" main effect of scope, $\left.X^{2}(1)=50.23, p<.001\right)$. These responses did not vary by domain (domain $\mathrm{x}$ scope interaction, $X^{2}(1)=0.92, p=.34$; main effect of domain, $\left.X^{2}(1)=0.21, p=.65\right)$. Thus, although adults believed that individual people or animals might vary, they saw conforming to groups as a matter of choice. 


\section{Discussion}

Consistent with Study 1, children disapproved of nonconformity in groups of people and groups of animals at similar rates, and they disapproved of nonconformity in groups of people more than adults did. However, unlike in Study 1 (and contrary to our preregistered hypothesis), adults also disapproved of nonconformity in groups of animals, at similar rates as children. This pattern of developmental continuity, though counter to Study 1 , is similar to that found in prior work on prescriptive judgments of familiar animals (Haward et al., 2018; see also Prasada \& Dillingham, 2006; 2009); we discuss this pattern further in the General Discussion.

In the Individual conditions, we found that children responded similarly to nonconforming people and animals, when visual cues to category membership were held constant. Following the rationale described in our pre-registration plan, this suggests that the domain differences that we observed in Study 1 in these conditions reflected differences in whether children recognized individuals as members of distinct kinds based on the perceptual information available (i.e., in Study 1 , the animals were more recognizable as distinct kinds based on just perceptual properties; this was controlled in Study 2 by not providing pictures of the stimuli). Thus, the findings from Study 2 suggest that when there are equivalent cues to category membership across domains, children reason prescriptively in a similar way about conformity.

Overall, participants disapproved of nonconformity in individuals more than in Study 1 (although still less than in groups). This is perhaps because the categories were described as "kinds" of animals or people in the introduction to the individual condition here, so even though participants considered only individuals, they realized the individuals were from different kinds (whereas in Study 1, they might have just been seen as individuals, not as representatives of different kinds). Yet, although the individual condition in Study 2 explicitly referred to the people or animals behind each door as being of different kinds, participants still just saw one example of a category member doing a particular behavior. In this way, they were faced with the question 
of whether one individual category member's behavior is indicative of how the group as a whole should behave. Indeed, children were less disapproving of non-conformity after learning about just one individual than they were after learning about multiple members of a category, and their responses were highly similar across domains. The distribution of adults' "OK" responses in the individual conditions in Study 2 was generally binary-some adults mostly approved of nonconformity, whereas others mostly disapproved-suggesting individual variation in the extent to which adults treated the behavior of individuals as standing in for the group as a whole (Figure 4). Thus, overall, the pattern of findings across conditions and studies suggests that children reject behavior that they view as violating prescriptive expectations of categories, in a manner that is largely similar across domains. The findings also suggest that approaches to non-conformity may become more flexible by adulthood when reasoning about novel categories.

\section{General Discussion}

Young children's strong attention to and consideration of prescriptive norms is an earlyemerging aspect of social cognition (Piaget, 1932; Rakoczy \& Schmidt, 2013; Rakoczy et al., 2008; Rutland et al., 2010; Searle, 1995; Smetana, 1981). The current data suggest that children's early emphasis on prescriptive norms extends beyond their reasoning about human social behavior and representations of human social categories, to shape how children represent categories of animals as well. To the extent that participants viewed novel properties as characteristic of their categories_-and viewed those categories as meaningful—they judged that individual category members ought to display those properties, for categories of both people and animals (see also Haward et al., 2018; Prasada \& Dillingham, 2006; 2009).

In Study 1, children often thought that members of novel animal and human categories should conform to their groups, even after seeing just one example per category. In Study 2, they again disapproved of nonconformity after learning about multiple examples of animals or people. After learning about just one example — this time in the absence of information about 
what category members look like (but with the categories explicitly described as "kinds")—they also disapproved of nonconformity for both animals and people, although less than when they observed the behavior in multiple category members. These findings suggest that children disapprove of nonconformity when they recognize the examples as members of different kinds (and even more so when they have evidence of the behavior across multiple category members). Across both studies, domain-specificity in children's judgments arose only in one instance-they were more likely to disapprove of nonconformity for animals after a single example, in Study 1 only. Based on Study 2, this likely occurred because they recognized the animals, but not the people, as members of different kinds in the Individual condition of that study. Thus, overall, the patterns were very similar across domains.

These findings do not indicate that prescriptive judgments of animal categories are exactly the same as prescriptive judgments of social categories. Although children generally disapproved of nonconformity across domains, they expected its consequences to vary. In Study 2, children more often predicted that nonconformity would result in functional harm for animals than people. This suggests that children's use of prescriptive information is not merely due to an undifferentiated bias (e.g., to reject all category irregularities), or the application of social norms outside of the social domain, but rather reflects how a more general conceptual bias to assume that categories mark not just how their members are, but also how they are supposed to be, becomes instantiated within children's domain-specific theories (Murphy \& Medin, 1985).

We do not think that children responded similarly to categories of animals and people in the present studies because they construed the stimuli across domains as representing the same types of category. For example, one concern could be that because children recognize nonhuman animals as social agents and are frequently exposed to anthropomorphized animal characters through children's media, that they reasoned about the presented animal categories as conventionalized social categories rather than biological entities. If this were the case, the 
present findings would not indicate an extension of prescriptive reasoning much beyond what has been documented in prior work. We think this is unlikely for several reasons. First, as noted above, children (and adults) predicted different consequences of non-conformity for categories of animals and people (and rarely predicted social harm for animals), suggesting that they indeed understood the stimuli as intended, as representing categories in different domains. Second, children's responses to animals were very similar for both the cartoon animals in Study 1 and the animals in Study 2, which were not shown but were introduced with a collage containing photographs of real, familiar animals—notable here because cartoon animals, not images of real animals, are frequently presented as anthropomorphized characters in children's media. Third, even in Study 1, the animals in the different categories had perceptual cues indicating that they were different species categories (as did the photographs used to introduce the domain in Study 2). Thus, we do not think that children in the present study responded similarly to animals and people because they thought of the animals as just like people, but rather because they have a more general tendency to assume that categories mark what features their members are supposed to have, which then shapes their category representations across these two different domains.

Whereas the present studies suggest that prescriptive expectations about categories extend beyond children's representations of human social categories, in future work, it will be necessary to explore how broadly these effects extend in early conceptual representations. For example, one possibility is that children expect categories to prescribe what their members are supposed to do more for categories they expect to be highly homogeneous (e.g., categories for which they hold essentialist beliefs, which includes both animal categories and some human social categories, as well as some other natural categories like plants) but not for those they view as more variable and flexible (e.g., categories of human-made artifacts). Another possibility is that children hold prescriptive expectations for categories whose members they view as intentional agents (which again, could cover animals and human social categories, but would 
exclude other natural categories as well as artifacts, and might even vary across human social groups and animal species depending on children's beliefs about the cognitive capacities of different people and animals). Yet a third possibility is that these judgments reflect very general biases to expect that categories (perhaps especially labeled categories) prescribe how things should be and thus are found quite broadly across conceptual domains. These questions are beyond the scope of the present work and will be important to examine in future studies.

These various accounts highlight how prescriptive expectations might arise not only from beliefs about particular property-kind relations (Haward et al., 2018; Prasada \& Dillingham, 2006; 2009), but also from beliefs about the causal structure of kinds in general (i.e., essentialist beliefs; Gelman \& Roberts, 2017; Rhodes \& Gelman, 2009). This interpretation could explain why children are more likely to disapprove of nonconformity when they see two novel categories as fundamentally distinct, but not otherwise. In the present studies, adults' predictions that nothing bad would result from nonconformity varied by scope but not domain: They often attributed nonconformity in individuals to variation, but they tended to view conforming to groups as a matter of choice_-for both people and animals. Would their responses be similar for familiar categories (e.g., judgments of gender nonconformity)? Compared to children, adults are more likely to attribute familiar human characteristics, such as athleticism, to genes (Meyer et al., 2020), suggesting that they may not always see conformity as a matter of choice even for people. Future research should examine how normative judgments across domains relate to beliefs about underlying category structure, including causal determinism, agency, and free will.

Despite the similarities in participants' responses across domains in the present studies, the consequences of prescriptive reasoning about the biological and social categories that people encounter in daily life are very different. People might see nonconformity among animals as funny, cute, or perplexing (e.g., consider people's responses to a cat that plays fetch), although prescriptive reasoning about animal categories might also foster beliefs that variation indicates progression toward an ideal, which hinder accurate scientific reasoning (Coley \& 
Tanner, 2015; Gelman \& Rhodes, 2012; Kelemen, 2012; Mayr, 1982). In contrast, prescriptive beliefs about social kinds can entail moral obligations and maintenance of group cohesion, and responses to nonconformity among social categories can elicit far more pernicious (even dangerous) responses, such as anger, fear, or disgust (Levy et al., 1995; Liben et al., 2001; Rhodes, 2012; Rutland et al., 2015). Further, people often use prescriptive expectations in the social domain to justify and reinforce social hierarchies, reasoning that if a social group is in power, it should be in power (Kay et al., 2009). Thus, people's prescriptive reasoning about social and biological kinds, while possibly originating in common cognitive mechanisms, differs importantly in their manifestation and consequences.

Overall, across studies, we found evidence of age-related change towards increased acceptance of nonconformity, consistent with prior work. Although adults in Study 1 generally approved of nonconformity (as in Roberts et al., 2017a), in Study 2-contrary to our preregistered hypothesis_-adults judged that animals should conform to groups, and they more often predicted that nonconformity would have negative consequences for animals than people. Why did adults disapprove of nonconformity among groups of animals more in Study 2 than in Study 1 ? One possible explanation, which we offer post-hoc (and therefore would need to be tested directly), is that this is because the introductory materials to Study 2 , which presented a collage of familiar animal categories, led them to draw more on their prior knowledge and beliefs about animal categories than did the fictional animals presented in Study 1. In prior work, adults have shown prescriptive reasoning about biological categories when they are asked to draw on their prior knowledge. For example, adults judge that dogs are supposed to bark, and there is something wrong with a dog that does not, at similar rates as young children (Haward et al., 2018; Prasada \& Dillingham 2006; 2009). Similarly, adults and 5- to 10-year-old children all judged that animals displaying extreme values of characteristic features are the "best" of their kinds (e.g., the giraffe with the longest neck; Foster-Hanson \& Rhodes, 2019a). Adults might find it easier to override prescriptive expectations and instead reason descriptively when they 
lack prior knowledge that reinforces the strength and nature of the categories and features, as was the case in Study 1. In prior work, the extent to which adults show other related conceptual biases (such as teleological thought in the biological domain and essentialism in the social domain) has been found to vary greatly across tasks, contexts, education, and cognitive ability (Atran, 1994; Kelemen \& Rosset, 2009; Kelemen et al., 2013; Lombrozo et al., 2007; Sánchez Tapia et al., 2016; Ware \& Gelman, 2014).

Further highlighting how adults' responses might depend on their prior beliefs and knowledge, here we found, as in previous studies (Roberts et al., 2017a), that adults held more flexible beliefs about social nonconformity than did young children. But adults hold prescriptive views about many familiar social categories, from judgments about who should and should not wear nail polish (Blakemore, 2003; Eagly, 2013) to judgments about who is a good leader (Brescoll \& Uhlmann, 2008; Eagly \& Karau, 2002; Heilman, 2012), and they expect members of many social categories to conform to group norms (e.g., Durkee et al., 2019). Although adults can be quite vocal about their prescriptive social judgments (Brady et al., 2017; Okimoto \& Brescoll, 2010), some of these views only become apparent when task demands are high (or when measured implicitly; Baron \& Banaji, 2006; Phillips \& Cushman, 2017). For instance, in speeded judgment tasks, adults often endorse more homogeneous views of categories—similar to young children—about both familiar animal kinds (e.g., Kelemen \& Rosset, 2009) and familiar social kinds (e.g., Eidson \& Coley, 2014; but see also Roberts \& Horii, 2019, for contrasting findings with children). Together, the results of the present study and of prior work raise the possibility that age-related changes towards increased acceptance of non-conformity relate to changes across development in the evidence required to see novel kinds as meaningful, and changes in people's beliefs about when it is appropriate to disapprove of others, rather than a decrease in prescriptive reasoning per se.

One limitation of the current design is that the measure of prescriptive judgments used here (and in previous work, i.e., asking whether nonconformity is "OK" or not) may be too broad 
to distinguish between different types of prescriptive reasoning. In previous work using this same measure (Roberts, Ho, \& Gelman; 2017), children were explicitly asked what it means for something to be "not OK," and the majority of children gave some kind of prescriptive explanation (e.g., "it's bad," "not allowed," "mommy will get upset," etc.). However, despite largely similar patterns of prescriptive judgments across domains, the explanation results in Study 2 suggest that children and adults may tend to engage in distinct forms of prescriptive reasoning about social and biological kinds (i.e., social reasoning vs. functional reasoning). While these forms of reasoning may be more common for one domain or another, it is also possible that different types of prescriptive reasoning are not strictly constrained by the domain under consideration, and that people can engage in different forms of reasoning flexibly depending on context. For example, people come to view some social categories as having a biological basis (e.g., gender, sexual orientation, mental illness); reasoning about human behavior as the product of genes (or placeholder "essences") might give rise to starkly different prescriptive reasoning than thinking in terms of purely social distinctions (Ahn et al., 2006; Fast \& Olson, 2018; Haslam \& Levy, 2006). This flexibility may also apply to reasoning about a single category at different levels of categorization—by dividing category members into different groups (e.g., different breeds of dogs, different "kinds" of people) or uniting them into a single group (e.g., dogs, humans)—with different levels of reasoning leading to different normative judgments. Future research should directly explore the flexibility of people's normative reasoning about different categories and domains.

In addition to different types of prescriptive reasoning (i.e., different frameworks through which people can explain why certain behaviors are bad), there may also be different types of prescriptive judgments (i.e., different types of bad behaviors). Evaluative judgments (e.g., what it is good to do) and deontic judgments (e.g., what one ought to do) are both prescriptive in that they rely on comparison to a normative standard, but they might also differ in important ways that align with people's over-hypotheses about the general structure of each domain. For 
example, in contrast to evaluative judgments, deontic obligations may entail social consequences for violation, such as punishment, and apply exclusively to agents who possess the free will to act otherwise (i.e., "ought" implies "can", or the Principle of Alternate Possibilities; Kant, 1781 see also Frankfurt, 1969; Sinnott-Armstrong, 1984). Yet there is considerable disagreement among both psychologists and philosophers about these distinctions, including whether evaluative and deontic judgements are the same kind of thing or distinct (Darwal, 2001; Malle, 2020; Moore, 1903; Tappolet, 2013). Some philosophers have even argued that all normative judgments are instrumental, and that acts can only be judged right or wrong relative to functions and goals (Hume, 1882; see also Setiya, 2004). Given this controversy, it is unclear which type of judgment best describes the current results, or how these distinctions among types of normativity apply across the existing developmental literature. Future research incorporating these perspectives might shed light on both this debate and the development of normative judgments in general.

In summary, across two domains, people sometimes think of categories not only as they are, but also as they should be. For children in particular, these prescriptive expectations can arise even from limited evidence-sometimes just a single category exemplar. Prescriptive judgments about how things ought to be can have far-reaching consequences, both within the social domain and beyond. Thus, understanding prescriptive reasoning across development and domains is crucial to the study of how categories shape human thought. 


\section{References}

Ahn, W. K., Flanagan, E. H., Marsh, J. K., \& Sanislow, C. A. (2006). Beliefs about essences and the reality of mental disorders. Psychological Science, 17(9), 759-766. https://doi.org/10.1111/j.1467-9280.2006.01779.x

Atran, S. (1994). Core domains versus scientific theories: Evidence from systematics and ItzaMaya folkbiology. Mapping the Mind: Domain Specificity in Cognition and Culture, 316340.

Baldwin, D. A. (1989). Priorities in children's expectations about object label reference: Form over color. Child Development, 60(6), 1291-1306. http://dx.doi.org/10.2307/1130921

Baron, A. S., \& Banaji, M. R. (2006). The development of implicit attitudes: Evidence of race evaluations from ages 6 and 10 and adulthood. Psychological Science, 17(1), 53-58. https://doi.org/10.1111/j.1467-9280.2005.01664.x

Barsalou, L. W. (1985). Ideals, central tendency, and frequency of instantiation as determinants of graded structure in categories. Journal of Experimental Psychology: Learning, Memory, and Cognition, 11(4), 629-654. https://doi.org/10.1037/0278-7393.11.1-4.629

Bates, D., Maechler, M., Bolker, B., \& Walker, S. (2015). Fitting linear mixed-effects models using Ime4. Journal of Statistical Software, 67(1), 1-48. http://dx.doi.org/10.18637/jss.v067.i01

Blakemore, J. E. O. (2003). Children's beliefs about violating gender norms: Boys shouldn't look like girls, and girls shouldn't act like boys. Sex Roles, 48(9-10), 411-419. https://doi.org/10.1023/A:1023574427720

Bloom, P. (2007). Religion is natural. Developmental Science, 10, 147151. https://doi.org/10.1111/j.1467-7687.2007.00577.x

Brady, W. J., Wills, J. A., Jost, J. T., Tucker, J. A., \& Van Bavel, J. J. (2017). Emotion shapes the diffusion of moralized content in social networks. Proceedings of the National 
Academy of Sciences, 114(28), 7313-7318. https://doi.org/10.1073/pnas.1618923114

Brandone, A. C. (2017). Changes in beliefs about category homogeneity and variability across childhood. Child Development, 88(3), 846-866. https://doi.org/10.1111/cdev.12616

Brescoll, V. L., \& Uhlmann, E. L. (2008). Can an angry woman get ahead? Status conferral, gender, and expression of emotion in the workplace. Psychological Science, 19(3), 268275. https://doi.org/10.1111/j.1467-9280.2008.02079.x

Burnett, R. C., Medin, D. L., Ross, N. O., \& Blok, S. V. (2005). Ideal is typical. Canadian Journal of Experimental Psychology/Revue Canadienne de Psychologie Expérimentale, 59(1), 3-10. https://doi.org/10.1037/h0087453.

Carey, S. (1985). Conceptual change in childhood. MIT press.

Chalik, L., \& Rhodes, M. (2015). The communication of naïve theories of the social world in parent-child conversation. Journal of Cognition and Development, 16(5), 719-741. https://doi.org/10.1080/15248372.2014.949722

Chernyak, N., Kushnir, T., Sullivan, K. M., \& Wang, Q. (2013). A comparison of American and Nepalese children's concepts of freedom of choice and social constraint. Cognitive Science, 37(7), 1343-1355. http://dx.doi.org/10.1111/cogs.12046

Christensen, R. H. B. (2019). ordinal - Regression Models for Ordinal Data. R package version 2019.4-25. http://www.cran.r-project.org/package=ordinal/.

Clément, F., Bernard, S., \& Kaufmann, L. (2011). Social cognition is not reducible to theory of mind: When children use deontic rules to predict the behaviour of others. British Journal of Developmental Psychology, 29(4), 910-928. https://doi.org/10.1111/j.2044835X.2010.02019.x

Coley, J. D., Hayes, B., Lawson, C., \& Moloney, M. (2004). Knowledge, expectations, and inductive reasoning within conceptual hierarchies. Cognition, 90(3), 217-253. https://doi.org/10.1016/S0010-0277(03)00159-8 
Coley, J. D., \& Tanner, K. (2015). Relations between intuitive biological thinking and biological misconceptions in biology majors and nonmajors. CBE Life Sciences Education, 14(1), ar8. https://doi.org/10.1187/cbe.14-06-0094

Dahl, A., \& Campos, J. J. (2013). Domain differences in early social interactions. Child Development, 84(3), 817-825. https://doi.org/10.1111/cdev.12002

Darwall, S. (2001). Because I want it. Social Philosophy and Policy, 18(2), 129-153.

Diesendruck, G., \& Deblinger-Tangi, R. (2014). The linguistic construction of social categories in toddlers. Child Development, 85(1), 114-123. https://doi.org/10.1111/cdev.12130

DiYanni, C., \& Kelemen, D. (2005). Time to get a new mountain? The role of function in children's conceptions of natural kinds. Cognition, 97(3), 327-335. https://doi.org/10.1016/j.cognition.2004.10.002

Dunham, Y., Stepanova, E. V., Dotsch, R., \& Todorov, A. (2015). The development of racebased perceptual categorization: Skin color dominates early category judgments. Developmental Science, 18(3), 469-483. https://doi.org/10.1111/desc.12228

Durkee, M. I., Gazley, E. R., Hope, E. C., \& Keels, M. (2019). Cultural invalidations:

Deconstructing the "acting White" phenomenon among Black and Latinx college students. Cultural Diversity and Ethnic Minority Psychology. https://doi.org/10.1037/cdp0000288

Eagly, A. H. (2013). Sex differences in social behavior: A social-role interpretation. Psychology Press.

Eagly, A. H., \& Karau, S. J. (2002). Role congruity theory of prejudice toward female leaders. Psychological Review, 109(3), 573. https://doi.org/10.1037/0033295X.109.3.573

Eidson, R. C., \& Coley, J. D. (2014). Not so fast: Reassessing gender essentialism in young adults. Journal of Cognition and Development, 15(2), 382-392. https://doi.org/10.1080/15248372.2013.763810 
Emmons, N. A., \& Kelemen, D. A. (2015). Young children's acceptance of within-species variation: Implications for essentialism and teaching evolution. Journal of Experimental Child Psychology, 139, 148-160. http://dx.doi.org/10.1016/j.jecp.2015.05.011

Evans, E. M. (2001). Cognitive and contextual factors in the emergence of diverse belief systems: Creation versus evolution. Cognitive Psychology, 42(3), 217-266. doi: 10.1006/cogp.2001.0749

Foster-Hanson, E., \& Rhodes, M. (2019a). Is the most representative skunk the average or the stinkiest? Developmental changes in representations of biological categories. Cognitive Psychology, 110, 1-15. https://doi.org/10.1016/j.cogpsych.2018.12.004

Foster-Hanson, E., \& Rhodes, M. (2019b). Normative Social Role Concepts in Early Childhood. Cognitive Science, 43(8): 1-18. https://doi.org/10.1111/cogs.12782

Foster-Hanson, E. ${ }^{*}$, Moty, K.*, Cardarelli, A., Ocampo, J. D., \& Rhodes, M. (2020). Developmental changes in strategies for gathering evidence about biological kinds. Cognitive Science, 44(5), e12837. https://doi.org/ 10.1111/cogs.12837

Frankfurt, H. G. (1969). Alternate possibilities and moral responsibility. The Journal of Philosophy, 66(23), 829-839. https://doi.org/10.2307/2023833

Gelman, S. A., \& Coley, J. D. (1990). The importance of knowing a dodo is a bird: Categories and inferences in 2-year-old children. Developmental Psychology, 26(5), 796. http://dx.doi.org/10.1037/0012-1649.26.5.796

Gelman, S. A., Croft, W., Fu, P., Clausner, T., \& Gottfried, G. (1998). Why is a pomegranate an apple? The role of shape, taxonomic relatedness, and prior lexical knowledge in children's overextensions of apple and dog. Journal of Child Language, 25(2), 267-291. https://doi.org/10.1017/S0305000998003420

Gelman, S. A., \& Kalish, C. W. (2007). Conceptual development. In D. Kuhn, R. S. Siegler, W. Damon, \& R. M. Lerner (Eds.), Handbook of child psychology, Vol. 2. Cognition, perception, and language (6th ed., pp. 687-733). Hoboken, NJ: Wiley. 
https://doi.org/10.1002/9780470147658.chpsy0216

Gelman, S. A., \& Markman, E. M. (1986). Categories and induction in young children. Cognition, 23(3), 183-209. https://doi.org/10.1016/0010-0277(86)90034-X

Gelman, S. A., \& Noles, N. S. (2011). Domains and naïve theories. Wiley Interdisciplinary Reviews: Cognitive Science, 2(5), 490-502. https://doi.org/10.1002/wcs.124

Gelman, S. A., \& Rhodes, M. (2012). Two-thousand years of stasis: How psychological essentialism impedes evolutionary understanding. In K. S. Rosengren, S. K. Brem, E. M. Evans \& G. M. Sinatra (Eds.), Evolution Challenges: Integrating research and practice in teaching and learning about evolution (pp. 3-21). Oxford: Oxford University Press. https://doi.org/10.1093/acprof:oso/9780199730421.003.0001

Gelman, S. A., \& Roberts, S. O. (2017). How language shapes the cultural inheritance of categories. Proceedings of the National Academy of Sciences, 114, 7900-7907. https://doi.org/10.1073/pnas.1621073114

Guthrie, S. E. (1993). Faces in the clouds. New York, NY: Oxford University Press.

Fast, A. A., \& Olson, K. R. (2018). Gender development in transgender preschool children. Child Development, 89(2), 620-637. https://doi.org/10.1111/cdev.12758

Haslam, N., \& Levy, S. R. (2006). Essentialist beliefs about homosexuality: Structure and implications for prejudice. Personality and Social Psychology Bulletin, 32(4), 471-485. https://doi.org/10.1177/0146167205276516

Haward, P., Wagner, L., Carey, S., \& Prasada, S. (2018). The development of principled connections and kind representations. Cognition, 176, 255-268. https://doi.org/10.1016/j.cognition.2018.02.001

Heilman, M. E. (2012). Gender stereotypes and workplace bias. Research in Organizational Behavior, 32, 113-135. https://doi.org/10.1016/j.riob.2012.11.003

Herrmann, P., Waxman, S. R., \& Medin, D. L. (2010). Anthropocentrism is not the first step in children's reasoning about the natural world. Proceedings of the National Academy of 
Sciences, 107, 9979-9984. https://doi.org/10.1073/pnas.1004440107

Hume, D. (1882). A treatise of human nature: Being an attempt to introduce the experimental method of reasoning into moral subjects and dialogues concerning natural religion $(T . H$. Green \& T. H. Grose, Eds.). London: Longmans, Green.

Hirschfeld, L. A. (1995). The inheritability of identity: Children's understanding of the cultural biology of race. Child Development, 66, 1418-1437. https://doi.org/10.1111/j.14678624.1995.tb00943.x

Hirschfeld, L.A. (1996). Race in the making: Cognition, culture, and the child's construction of human kinds. Cambridge, MA: The MIT Press.

Kalish, C. (1998). Reasons and causes: Children's understanding of conformity to social rules and physical laws. Child Development, 69(3), 706-720.

http://dx.doi.org/10.2307/1132199

Kalish, C. W. (2012). Generalizing norms and preferences within social categories and individuals. Developmental Psychology, 48(4), 1133. http://dx.doi.org/10.1037/a0026344

Kalish, C. W., \& Cornelius, R. (2007). What is to be done? Children's ascriptions of conventional obligations. Child Development, 78(3), 859-878. https://doi.org/10.1111/j.14678624.2007.01037.x

Kalish, C. W., \& Lawson, C. A. (2008). Development of social category representations: Early appreciation of roles and deontic relations. Child Development, 79(3), 577-593. https://doi.org/10.1111/j.1467-8624.2008.01144.x

Kant, I. (1781). Critique of pure reason (P. Guyer and A. W. Wood, Trans. and Eds.). New York: Cambridge University Press.

Kay, A. C., Gaucher, D., Peach, J. M., Laurin, K., Friesen, J., Zanna, M. P., \& Spencer, S. J. (2009). Inequality, discrimination, and the power of the status quo: Direct evidence for a motivation to see the way things are as the way they should be. Journal of Personality and Social Psychology, 97(3), 421-434. https://doi.org/10.1037/a0015997 
Keil, F. C. (1992). Concepts, kinds, and cognitive development. Cambridge, MA: MIT Press.

Kelemen, D. (1999). Why are rocks pointy? Children's preference for teleological explanations of the natural world. Developmental Psychology, 35(6), 1440-1452. http://dx.doi.org/10.1037/0012-1649.35.6.1440

Kelemen, D. (2004). Are children "intuitive theists"? Reasoning about purpose and design in nature. Psychological Science, 15(5), 295-301. https://doi.org/10.1111/j.09567976.2004.00672.x

Kelemen, D. (2012). Teleological minds: How natural intuitions about agency and purpose influence learning about evolution. In K. S. Rosengren, S. K. Brem, E. M. Evans \& G. M. Sinatra (Eds.), Evolution challenges: Integrating research and practice in teaching and learning about evolution. Oxford: Oxford University Press.

Kelemen, D., \& Rosset, E. (2009). The human function compunction: Teleological explanation in adults. Cognition, 111(1), 138-143. https://doi.org/10.1016/j.cognition.2009.01.001

Kelemen, D., Rottman, J., \& Seston, R. (2013). Professional physical scientists display tenacious teleological tendencies: Purpose-based reasoning as a cognitive default. Journal of Experimental Psychology: General, 142(4), 1074-1083. https://doi.org/10.1037/a0030399.

Kenward, B., Karlsson, M., \& Persson, J. (2011). Over-imitation is better explained by norm learning than by distorted causal learning. Proceedings. Biological Sciences, 278(1709), 1239-1246. https://doi.org/10.1098/rspb.2010.1399

Kim, S., \& Murphy, G. L. (2011). Ideals and category typicality. Journal of Experimental Psychology: Learning, Memory, and Cognition, 37(5), 1092-1112. https://doi.org/10.1037/a0023916

Levesque, H., Davis, E., \& Morgenstern, L. (2012, May). The winograd schema challenge. In Brewka, G., Eiter, T., \& Mcllraith, S. (Eds). Proceedings of the Thirteenth International Conference on the Principles of Knowledge Representation and Reasoning. Rome, Italy: 
AAAI Publications.

Levy, G. D., Taylor, M. G., \& Gelman, S. A. (1995). Traditional and evaluative aspects of flexibility in gender roles, social conventions, moral rules, and physical laws. Child Development, 66(2), 515-531. https://doi.org/10.1111/j.1467-8624.1995.tb00887.x

Liben, L. S., Bigler, R. S., \& Krogh, H. R. (2001). Pink and blue collar jobs: Children's judgments of job status and job aspirations in relation to sex of worker. Journal of Experimental Child Psychology, 79(4), 346-363. https://doi.org/10.1006/jecp.2000.2611

Lombrozo, T., Kelemen, D., \& Zaitchik, D. (2007). Inferring design: Evidence of a preference for teleological explanations in patients with Alzheimer's disease. Psychological Science, 18(11), 999-1006. https://doi.org/10.1111/j.1467-9280.2007.02015.x

Lynch, E. B., Coley, J. D., \& Medin, D. L. (2000). Tall is typical: Central tendency, ideal dimensions, and graded category structure among tree experts and novices. Memory \& Cognition, 28(1), 41-50. https://doi.org/10.3758/BF03211575.

Lyons, D. E., Young, A. G., \& Keil, F. C. (2007). The hidden structure of overimitation. Proceedings of the National Academy of Sciences of the United States of America, 104(50), 19751-19756. https://doi.org/10.1073/pnas.0704452104

Malle, B. F. (2021). Moral judgments. Annual Review of Psychology, 72, 293-318.

Mandalaywala, T. M., Ranger-Murdock, G., Amodio, D. M., \& Rhodes, M. (2019). The nature and consequences of essentialist beliefs about race in early childhood. Child Development, 90(4), e437-e453. https://doi.org/10.1111/cdev.13008

Mayr, E. (1982). The growth of biological thought: Diversity, evolution, and inheritance. Cambridge, MA: Harvard University Press.

Medin, D. L., \& Atran, S. (2004). The Native Mind: Biological Categorization and Reasoning in Development and Across Cultures. Psychological Review, 111(4), 960-983. https://doi.org/10.1037/0033-295X.111.4.960

Medin, D., Waxman, S., Woodring, J., \& Washinawatok, K. (2010). Human-centeredness is not 
a universal feature of young children's reasoning: Culture and experience matter when reasoning about biological entities. Cognitive Development, 25(3), 197-207. https://doi.org/10.1016/j.cogdev.2010.02.001

Mervis, C., \& Pani, J. (1980). Acquisition of basic object categories. Cognitive Psychology, 12, 496-522. http://dx.doi.org/10.1016/ 0010-0285(80)90018-3

Meyer, M., Roberts, S. O., Jayaratne, T. E., \& Gelman, S. A. (2020). Children's beliefs about causes of human characteristics: Genes, environment, or choice?. Journal of Experimental Psychology: General, 149(10), 1935-1949. https://doi.org/10.1037/xge0000751

Moore, G. E. (1903). Principia Ethica: Vol. 2 (1959). Cambridge University Press.

Murphy, G. L., \& Medin, D. L. (1985). The role of theories in conceptual coherence. Psychological Review, 92(3), 289.

Nielsen, M., \& Tomaselli, K. (2010). Overimitation in Kalahari Bushman children and the origins of human cultural cognition. Psychological Science, 21(5), 729-736. http://dx.doi.org/10.1177/0956797610368808

Okimoto, T. G., \& Brescoll, V. L. (2010). The price of power: Power seeking and backlash against female politicians. Personality and Social Psychology Bulletin, 36(7), 923-936. https://doi.org/10.1177/0146167210371949

Orvell, A., Kross, E., \& Gelman, S. A. (2017). How “you” makes meaning. Science, 355(6331), 1299-1302. https://doi.org/10.1126/science.aaj2014

Orvell, A., Kross, E., \& Gelman, S. A. (2018). That's how "you" do it: Generic you expresses norms during early childhood. Journal of Experimental Child Psychology, 165, 183-195. https://doi.org/10.1016/J.JECP.2017.04.015

Osherson, D. N., Smith, E. E., Wilkie, O., López, A., \& Shafir, E. (1990). Category-based induction. Psychological Review, 97(2), 185-200. https://doi.org/10.1037/0033$295 X .97 .2 .185$ 
Phillips, J., \& Cushman, F. (2017). Morality constrains the default representation of what is possible. Proceedings of the National Academy of Sciences of the United States of America, 114(18), 4649-4654. https://doi.org/10.1073/pnas.1619717114

Piaget, J. (1929). The child's conception of the world. New York, NY: Harcourt, Brace Jovanovich.

Piaget, J. (1932). The moral judgement of the child. London: Routledge \& Kegan Paul.

Prasada, S., \& Dillingham, E. M. (2006). Principled and statistical connections in common sense conception. Cognition, 99(1), 73-112. https://doi.org/10.1016/J.COGNITION.2005.01.003

Prasada, S., \& Dillingham, E. M. (2009). Representation of principled connections: A window onto the formal aspect of common sense conception. Cognitive Science, 33(3), 401448. https://doi.org/10.1111/j.1551-6709.2009.01018.x

Rakoczy, H. (2008). Taking fiction seriously: Young children understand the normative structure of joint pretence games. Developmental Psychology, 44(4), 1195. http://doi.org/10.1037/0012-1649.44.4.1195

Rakoczy, H., \& Schmidt, M. F. H. (2013). The early ontogeny of social norms. Child Development Perspectives, 7(1), 17-21. https://doi.org/10.1111/cdep.12010

Rakoczy, H., Warneken, F., \& Tomasello, M. (2008). The sources of normativity: Young children's awareness of the normative structure of games. Developmental Psychology, 44(3), 875. http://doi.org/10.1037/0012-1649.44.3.875

Rhodes, M. (2012). Naïve theories of social groups. Child Development, 83, 1900-1916. https://doi.org/10.1111/j.1467-8624.2012.01835.x

Rhodes, M. (2013). How two intuitive theories shape the development of social categorization. Child Development Perspectives, 7(1), 12-16. https://doi.org/10.1111/cdep.12007

Rhodes, M., \& Chalik, L. (2013). Social categories as markers of intrinsic interpersonal 
obligations. Psychological Science, 24(6), 999-1006.

https://doi.org/10.1177/0956797612466267

Rhodes, M., \& Gelman, S. A. (2009). A developmental examination of the conceptual structure of animal, artifact, and human social categories across two cultural contexts. Cognitive Psychology, 59(3), 244-274. https://doi.org/10.1016/J.COGPSYCH.2009.05.001

Rhodes, M., Gelman, S. A., \& Karuza, J. C. (2014). Preschool ontology: The role of beliefs about category boundaries in early categorization. Journal of Cognition and Development, 15(1), 78-93. https://doi.org/10.1080/15248372.2012.713875

Rhodes, M., Leslie, S. J., Bianchi, L., \& Chalik, L. (2018). The role of generic language in the early development of social categorization. Child Development, 89(1), 148-155. https://doi.org/10.1111/cdev.12714

Rhodes, M., \& Moty, K. (2020). What is social essentialism and how does it develop? In M. Rhodes (Ed.), Advances in child development and behavior, Vol. 29 (pp. 1-30). Academic Press. https://doi.org/10.1016/bs.acdb.2020.05.001

Rips, L. J. (1995). The current status of research on concept combination. Mind \& Language, 10(1-2), 72-104. https://doi.org/10.1111/j.1468-0017.1995.tb00006.x

Roberts, S. O., \& Gelman, S. A. (2015). Do children see in Black and White? Children's and adults' categorizations of multiracial individuals. Child Development, 86(6), 1830-1847. https://doi.org/10.1111/cdev.12410

Roberts, S. O., Gelman, S. A., \& Ho, A. K. (2017a). So it is, so it shall be: Group regularities license children's prescriptive judgments. Cognitive Science, 41, 576-600. https://doi.org/10.1111/cogs.12443

Roberts, S. O., Ho, A. K., \& Gelman, S. A. (2017b). Group presence, category labels, and generic statements influence children to treat descriptive group regularities as prescriptive. Journal of Experimental Child Psychology, 158, 19-31. https://doi.org/10.1016/J.JECP.2016.11.013 
Roberts, S. O., Ho, A. K., \& Gelman, S. A. (2019). The role of group norms in evaluating uncommon and negative behaviors. Journal of Experimental Psychology: General, 148, 374-387. https://doi.org/10.1037/xge0000534

Roberts, S. O., \& Horii, R. (2019). Thinking fast and slow: Children's descriptive-to-prescriptive tendency under varying time constraints. Journal of Cognition and Development, 20, 790-799. https://doi.org/10.180/15248372.2019.1599001

Rottman, J., \& Kelemen, D. (2012). Aliens behaving badly: Children's acquisition of novel puritybased morals. Cognition, 124(3), 356-360. http://dx.doi.org/10.1016/j.cognition.2012.06.001

Rutland, A., Hitti, A., Mulvey, K. L., Abrams, D., \& Killen, M. (2015). When does the in-group like the out-group? Bias among children as a function of group norms. Psychological Science, 26(6), 834-842. https://doi.org/10.1177/0956797615572758

Rutland, A., Killen, M., \& Abrams, D. (2010). A new social-cognitive developmental perspective on prejudice: The interplay between morality and group identity. Perspectives on Psychological Science, 5(3), 279-291. https://doi.org/10.1177/1745691610369468

Sánchez Tapia, I., Gelman, S. A., Hollander, M. A., Manczak, E. M., Mannheim, B., \& Escalante, C. (2016). Development of teleological explanations in Peruvian Quechuaspeaking and US English-speaking preschoolers and adults. Child Development, 87(3), 747-758. https://doi.org/10.1111/cdev.12497

Schmidt, M. F., Butler, L. P., Heinz, J., \& Tomasello, M. (2016). Young children see a single action and infer a social norm: Promiscuous normativity in 3-year-olds. Psychological Science, 27(10), 1360-1370. https://doi.org/10.1177/0956797616661182

Schmidt, M. F. H., \& Rakoczy, H. (2017). Developing an understanding of normativity. In A. Newen, L. de Bruin, \& S. Gallagher (Eds.), Oxford Handbook of Cognition: Embodied, Embedded, Enactive and Extended. Oxford: Oxford University Press.

Schmidt, M. F., Rakoczy, H., \& Tomasello, M. (2011). Young children attribute normativity to 
novel actions without pedagogy or normative language. Developmental Science, 14(3), 530-539. https://doi.org/10.1111/j.1467-7687.2010.01000.x

Searle, J. R. (1995). The construction of social reality. New York: Free Press.

Segall, G., Birnbaum, D., Deeb, I., \& Diesendruck, G. (2014). The intergenerational transmission of ethnic essentialism: How parents talk counts the most. Developmental Science, 18: 543-55. https://doi.org/10.1111/desc.12235

Setiya, K. (2004). Hume on practical reason. Philosophical Perspectives, 18, 365-389. http://www.jstor.org/stable/3840940

Shtulman, A., \& Harrington, K. (2016). Tensions between science and intuition across the lifespan. Topics in Cognitive Science, 8(1), 118-137. https://doi.org/10.1111/tops.12174.

Shtulman, A., \& Phillips, J. (2018). Differentiating "could" from "should": Developmental changes in modal cognition. Journal of Experimental Child Psychology, 165, 161-182. https://doi.org/10.1016/j.jecp.2017.05.012

Shtulman, A., \& Schulz, L. (2008). The relation between essentialist beliefs and evolutionary reasoning. Cognitive Science, 32(6), 1049-1062. https://doi.org/10.1080/03640210801897864

Shweder, R. A., Mahapatra, M., \& Miller, J. G. (1987). Culture and moral development. In J. Kagan \& S. Lamb (Eds.), The emergence of morality in young children (pp. 1-83). Chicago: University of Chicago Press.

Sinnott-Armstrong, W. (1984). 'Ought' conversationally implies 'can'. The Philosophical Review, 93(2), 249-261. https://doi.org/10.2307/2184585

Smetana, J. (1981). Preschool children's conceptions of moral and social rules. Child Development, 52, 1333-1336. https://doi.org/10.2307/1129527

Tappolet, C. (2013). Evaluative vs. Deontic Concepts. International Encyclopedia of Ethics.

Tisak, M. S., \& Turiel, E. (1988). Variation in seriousness of transgressions and children's moral and conventional concepts. Developmental Psychology, 24(3), 352-357. 
https://doi.org/10.1037/0012-1649.24.3.352

Tomasello, M. (2019a). The moral psychology of obligation. Behavioral and Brain Sciences. 133. https://doi.org/10.1017/S0140525X19001742.

Tomasello, M. (2019b). Becoming human: A theory of ontogeny. Cambridge, MA: Belknap Press.

Ware, E. A., \& Gelman, S. A. (2014). You get what you need: An examination of purpose-based inheritance reasoning in undergraduates, preschoolers, and biological experts. Cognitive Science, 38(2), 197-243. https://doi.org/10.1111/cogs.12097 